\title{
"IOGURTE" DE SOJA SUPLEMENTADO COM OLIGOFRUTOSE E INULINA ${ }^{1}$
}

\author{
Renata Hernandez Barros FUCHS ${ }^{2}$, Dionísio BORSATO ${ }^{3}$, Evandro BONA², \\ Maria Celia de Oliveira HAULY,*
}

\begin{abstract}
RESUMO
A população de um modo geral está mais consciente da relação existente entre alimentação e saúde. Sendo assim, a indústria busca novas alternativas para o desenvolvimento de alimentos de boa aceitabilidade e com ingredientes capazes de promover a saúde. A soja e prebióticos como oligofrutose e inulina possuem grande potencial de aplicação na indústria, devido as suas importantes propriedades funcionais. O objetivo deste trabalho foi determinar, utilizando a metodologia da superficie de resposta, as melhores condições para o desenvolvimento de um "iogurte" de soja suplementado com oligofrutose e inulina. Utilizou-se o delineamento fatorial incompleto $3^{3}$, tendo oligofrutose (\%), inulina (\%) e tempo de fermentação (h) como variáveis independentes e pH e acidez titulável como respostas. A análise de regressão mostrou que os modelos obtidos foram preditivos. A otimização conjunta bilateral apontou a formulação contendo $14,24 \%$ de oligofrutose, $4,43 \%$ de inulina e 6 horas como as melhores condições para o preparo de "iogurte" de soja. Essa formulação apresentou pH 4,6; acidez 0,37\%; 16,2\% de carboidratos; $2,01 \%$ de lipídeos; 3,54\% de proteinas; 0,40\% de cinzas e $77,85 \%$ de umidade. O teor de cálcio, ferro e sódio foram de 37; 0,99 e $15 \mathrm{mg} / 100 \mathrm{~g}$, respectivamente. Pode-se afirmar que oligofrutose e inulina podem ser utilizadas na suplementação de "iogurte" de soja, constituindo um produto com ingredientes potencialmente funcionais. Palavras-chave: iogurte; soja; oligofrutose; inulina; metodologia da superficie de resposta.
\end{abstract}

\section{SUMMARY}

SOY YOGURT SUPPLEMENTED WITH OLIGOFRUCTOSE AND INULIN. People are getting more conscious about the relationship between food and health. Consequently, industry looks for new alternatives to develop food with good acceptance and with ingredients able to improve health. Soy, prebiotics such as oligofructose and inulin have a great application potential in food industry due to their functional properties. The aim of this work was to determine, using the Surface Response Methodology, the best conditions to the development of a soy yogurt supplemented with oligofructose and inulin. A $3^{3}$ incomplete design was used, having oligofructose (\%), inulin (\%) and fermentation time (h) as independent variables, and $\mathrm{pH}$ and titrable acidity as responses. Regression analysis showed that models obtained were predictive. The optimization pointed out for the formulation containing $14.24 \%$ of oligofructose, $4.43 \%$ of inulin and 6 hours, as the best conditions to make soy yogurt. This formulation presented pH value of 4.6 and acidity of $0.37 \%$. The chemical compostion was $16.2 \%$ of carbohydrates $2.01 \%$ of fat; $3.54 \%$ of protein; $0.40 \%$ of ash; and $77.85 \%$ of moisture. Calcium, iron and sodium content were $37 ; 0.99$ and $15 \mathrm{mg} / 100 \mathrm{~g}$, respectively. Therefore, oligofructose and inulin may be used to supplement soy yogurt, resulting in a product with functional ingredients.

Keywords: yogurt; soy; oligofructose; inulin; surface response methodology.

\section{1 - INTRODUÇÃO}

Historicamente, o estado nutricional de populações que vivem em países desenvolvidos é afetado por hábitos inadequados como o consumo excessivo de gorduras, principalmente saturadas, elevada ingestão de açúcares e diminuição considerável do consumo de amido, fibras, vitaminas e sais minerais, que podem ser causadores da elevada incidência de doenças crônico-degenerativas nesses países [8].

Paralelamente a este fenômeno, observa-se um acelerado desenvolvimento de alimentos que apresentam, além de características nutricionais e tecnológicas adequadas, componentes que exercem funções biológicas com o intuito de prevenir doenças e promover a saúde, os alimentos funcionais [27]. Dentre os alimentos funcionais estudados destacam-se a soja, os probióticos e os prebióticos.

\footnotetext{
1. Recebido para publicação em 30/03/2004. Aceito para publicação em 31/01/2005 (001318).

2. Departamento de Bioquimica - UEL - Campus Universitário. CEP: 86051970 - Londrina- Paraná.

3. Departamneto de Química - UEL,Londrina-Paraná

* A quem a correspondência deve ser enviada.
}

A soja e seus derivados têm recebido atenção dos pesquisadores, principalmente devido à quantidade e qualidade de sua proteína, sendo considerada, dentre os vegetais, o melhor substituto de produtos de origem animal. Além disso, a soja é importante fonte de outros compostos, como fibras, oligossacarídeos com potencial prebiótico, como rafinose e estaquiose, vitaminas e minerais [7].

Probióticos são definidos como microrganismos viáveis que, quando aplicados a humanos ou animais, afetam beneficamente a saúde do hospedeiro, por promover um balanço da microbiota intestinal, sendo Lactobacillus e Bifidobacterium os gêneros mais utilizados como probióticos [ 15, 29]. Historicamente, a associação desses microrganismos com alimentos tem sido considerada segura, porém conforme relatado por MARTEAU [21] os probióticos podem, teoricamente, ser responsáveis por alguns efeitos colaterais como estimulação imunológica excessiva e infecções sistêmicas entre outros. Segundo FERREIRA [13] as espécies mais usadas em preparações probióticas são Lactobacillus acidophilus, L. casei, L. rhamnosus, L.reuterii, Enterococcus faecium, Bifidobacterium adolescentis, B.breve, B.bifidum, B.infantis, B.longum. KAYSER [18] ressaltou que a utilização de enterococos para produção de alimentos ou preparação de probióticos requer uma avaliação cuida- 
dosa com relação à segurança alimentar. Com a finalidade de elaborar instruções para avaliação de probióticos em alimentos e estabelecer critérios para garantir maior segurança alimentar, um grupo de especialistas em probióticos, convocados pela FAO/WHO [11], estabeleceu critérios e metodologias que são recomendadas para avaliação de probióticos.

De acordo com FULLER [15] L. bulgaricus $e$ Streptococcus thermophilus, são utilizados em preparações probióticas como culturas "starter" em iogurte e, são incluídos com base nos objetivos estabelecidos para o iogurte. FERREIRA [12] descreveu Lactobacillus delbrueckii spp.bulgaricus e Streptococcus thermophilus como culturas bioajustadoras de $\mathrm{pH}$ empregadas na fabricação de produtos lácteos fermentados probióticos, para que estas possam atingir uma acidez segura no período aceitável.

Entretanto, vários estudos têm chamado a atenção para o curto período de vida dos probióticos e para a contribuição dos prebióticos (oligofrutose, inulina, rafinose e estaquiose) no aumento da viabilidade dos microrganismos presentes no cólon [9, 20].

Prebióticos são componentes alimentares não digeriveis, geralmente oligossacarídeos, com atividade bifidogênica, ou seja, capazes de estimular o crescimento e/ou atividade de algumas bactérias presentes no intestino [16]. Entretanto, os prebióticos diferem em suas características fermentativas. RYCROFT et al. [29] avaliando as propriedades fermentativas de alguns prebióticos, verificaram que xilooligossacarídeos e lactulose produziram os maiores aumentos no número de bifidobactérias, enquanto os frutooligossacarídeos (FOS) propiciaram o desenvolvimento de lactobacilos e que a mistura deles pode aumentar sua funcionalidade. RASTALL \& MAITIN [25] também afirmaram que a utilização de frutooligossacarídeos (FOS) resultou num aumento populacional de lactobacilos.

Diante da procura dos consumidores por alimentos mais saudáveis, capazes de trazer beneficios extras à saúde, e dos potenciais efeitos benéficos da soja e dos prebióticos, este trabalho teve como objetivos determinar, utilizando a metodologia da superficie de resposta, as melhores condições para o desenvolvimento de "iogurte" de soja suplementado com oligofrutose e inulina e a composição química da melhor formulação obtida.

\section{2 - MATERIAL E MÉTODOS}

\section{1 - Material}

\subsection{1 - Prebióticos}

O "iogurte" de soja foi suplementado com os prebióticos oligofrutose (Raftilose P95) e inulina (Raftiline GR) fornecidos pela ORAFTI -Bélgica.

\subsection{2 - Matéria prima: extrato de soja em pó}

Para o preparo do "iogurte" foi utilizado extrato de soja em pó (Provesol PSA), cedido pela Olvebra. Este produto é um extrato protéico obtido a partir da emulsão aquosa de farinha de soja, submetida a tratamento térmico para inativação de fatores antinutricionais, sendo a fração solúvel, concentrada e seca.

A composição (em base seca) para $100 \mathrm{~g}$ do produto é de $19 \mathrm{~g}$ de carboidratos, $44 \mathrm{~g}$ de proteínas, $26 \mathrm{~g}$ de gorduras totais ( $5 \mathrm{~g}$ de gorduras saturadas), $1 \mathrm{~g}$ de fibras, $6 \mathrm{~g}$ de cinzas (40mg de sódio, 157mg de cálcio e 4,5mg de ferro), $4 \%$ de umidade e seu valor calórico é de 490kcal.

\subsection{3 - Microrganismos}

Para obtenção do "iogurte" foi utilizado o fermento lácteo Rich ${ }^{\circledR}$, constituído de culturas superconcentradas de Lactobacillus delbrueckii ssp bulgaricus e Streptococcus thermophilus, gentilmente fornecido pela Christian Hansen - Valinhos-SP.

\section{2 - Métodos}

\subsection{1 - Delineamento estatístico para desenvol- vimento dos experimentos}

Para a suplementação do "iogurte" de soja com oligofrutose e inulina foi empregada a metodologia da superficie de resposta, delineamento fatorial $3^{3}$ incompleto, para investigar o efeito de três variáveis independentes sobre as propriedades químicas e físicas do iogurte. O delineamento foi composto de 15 ensaios, com 3 repetições no ponto central (Tabela 1 ), representando $48 \%$ das combinações teóricas $\left(3^{3}=27\right)$, o que possibilita uma representação bastante precisa da realidade [3].

TABELA 1. Delineamento experimental para preparação do "iogurte" suplementado com oligofrutose e inulina

\begin{tabular}{|c|c|c|c|}
\hline \multirow{2}{*}{ Experimentos } & \multicolumn{3}{|c|}{ Variáveis codificadas } \\
\hline & $\mathrm{X}_{1}$ & $\mathrm{X}_{2}$ & $\mathrm{X}_{3}$ \\
\hline 1 & -1 & -1 & 0 \\
\hline 2 & 1 & -1 & 0 \\
\hline 3 & -1 & 1 & 0 \\
\hline 4 & 1 & 1 & 0 \\
\hline 5 & -1 & 0 & -1 \\
\hline 6 & 1 & 0 & -1 \\
\hline 7 & -1 & 0 & 1 \\
\hline 8 & 1 & 0 & 1 \\
\hline 9 & 0 & -1 & -1 \\
\hline 10 & 0 & 1 & -1 \\
\hline 11 & 0 & -1 & 1 \\
\hline 12 & 0 & 1 & 1 \\
\hline 13 & 0 & 0 & 0 \\
\hline 14 & 0 & 0 & 0 \\
\hline 15 & 0 & 0 & 0 \\
\hline Variáveis Símbolos & \multicolumn{3}{|c|}{ Níveis codificados } \\
\hline Independentes & -1 & 0 & 1 \\
\hline Oligofrutose (\%) $\mathrm{X}_{1}$ & 5 & 10 & 15 \\
\hline Inulina (\%) $X_{2}$ & 0,5 & 2,5 & 4,5 \\
\hline Tempo de fermentação (h) $X_{3}$ & 6 & 7 & 8 \\
\hline
\end{tabular}


As variáveis independentes oligofrutose $\left(\mathrm{X}_{1}\right)$, inulina $\left(\mathrm{X}_{2}\right)$ e tempo de fermentação $\left(\mathrm{X}_{3}\right)$ foram analisadas em 3 niveis eqüidistantes de variação e codificadas com $-1,0$ e 1 . Os niveis codificados das variáveis e seus valores reais estão demonstrados na Tabela 1 . As variáveis dependentes (respostas) $\mathrm{pH}$ e acidez titulável foram escolhidas por serem importantes parâmetros de qualidade para iogurte [12].

\subsection{2 - Preparo do substrato para o "iogurte" de soja suplementado com oligofrutose e inulina}

O extrato de soja em pó foi homogeneizado com água, na concentração de 10\% (m/v), em liquidificador, durante 5 minutos. O homogeneizado foi distribuido em recipientes de vidro que continham oligofrutose e inulina, nas quantidades indicadas pelo delineamento estatístico mostrado na Tabela 1 . O substrato submetido à fermentação apresentava valor médio de $\mathrm{pH}$ inicial igual a 7,0. Após a homogeneização, os recipientes foram tampados e colocados em autoclave, sob vapor fluente, durante 20 minutos.

\subsection{3 - Formulação controle para o "iogurte" de soja}

A formulação controle para o "iogurte" foi preparada com extrato de soja em pó na concentração de $10 \%$ (m/v) em água, sem adição de prebióticos.

\subsection{4 - Fermentação lática}

Após o resfriamento dos substratos até a temperatura de $42^{\circ} \mathrm{C}$, o inóculo de $0,16 \%$ de fermento lácteo (9log UFC. $\mathrm{mL}^{-1}$ ou $10^{9}$ UFC. $\mathrm{mL}^{-1}$ ) foi adicionado aos recipientes com extrato de soja e prebióticos. Os recipientes permaneceram em estufa em temperatura constante de $42^{\circ} \mathrm{C}$, para fermentação, durante o tempo definido pelo delineamento estatístico. A Figura 1 mostra o fluxograma para produção do "iogurte".

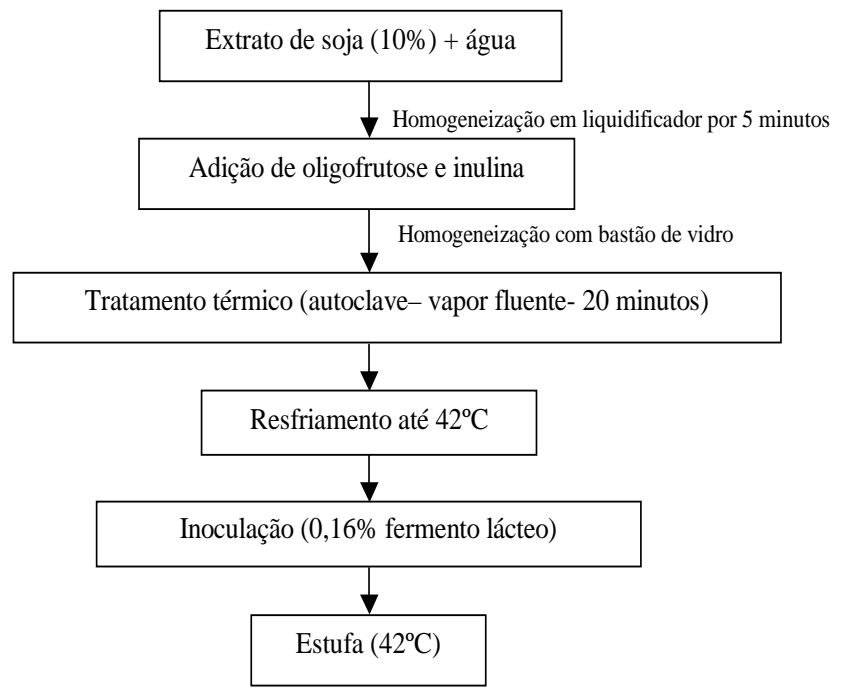

FIGURA 1. Fluxograma de produção do "iogurte" de soja suplementado.

\subsection{5 - Determinações analiticas para avaliação química e física dos "iogurtes"}

- Determinação do pH

O valor de $\mathrm{pH}$ das formulações de "iogurte" foi medido ao término do período de fermentação determinado pelo delineamento estatístico.

$\mathrm{O} \mathrm{pH}$ final dos diferentes "iogurtes" obtidos foi determinado, logo após o término da fermentação, através de potenciômetro digital (Microprocessor pHmeter HI 9321), previamente calibrado.

- Determinação da acidez titulável

A acidez foi determinada por titulação com solução de $\mathrm{NAOH} 0,1 \mathrm{~N}$, conforme AOAC (técnica $\mathrm{n}^{\circ}$ 970.124) [1] e expressa em \% de ácido lático. As amostras foram avaliadas, quanto à acidez, imediatamente à interrupção do processo fermentativo, determinado pelo delineamento estatístico.

- Determinação de ácido lático por espectrofotometria

O ácido lático foi extraído da formulação de "iogurte" otimizada de acordo com o método descrito por SILVA [30] e determinado por espectrofotometria, utilizando cloreto férrico como reativo de cor. O padrão para a curva de referência foi o lactato de lítio a $1 \%$, extraído nas mesmas condições.

- Determinação da composição química

O "iogurte" de soja suplementado com oligofrutose e inulina foi caracterizado quimicamente quanto à: umidade pelo método de secagem à vácuo; proteínas pelo método micro Kjedalh; lipídeos pelo método de Soxhlet; cinzas pelo método de cinzas secas e carboidratos totais, estimados por diferença [1].

Os minerais cálcio, ferro e sódio foram determinados por espectrofotometria de absorção atômica [1].

\subsection{6 - Análise estatística}

Os resultados foram avaliados por análise de variância (ANOVA) e foi aplicado teste de comparação de médias de Tukey $(\mathrm{p} \leq 0,05)$.

Os resultados obtidos no delineamento experimental para formulação dos "iogurtes" foram avaliados através da Metodologia da Superficie de Resposta e análise de variância (ANOVA), utilizando-se o programa Statistic for Windows versão 5 [31]. Para a otimização conjunta bilateral, utilizou-se o software Otplex [2] com incorporação das funções de DERRINGER \& SUICH [10].

\section{3 - RESULTADOS E DISCUSSÃO}

\section{1 - Delineamento experimental e otimização da formulação de "iogurte" de soja}

As respostas, expressas em valores médios de três repetições, dos 15 ensaios e da formulação controle para "iogurte" de soja são apresentados na Tabela 2. Os resultados foram avaliados pela análise de variân- 
cia (ANOVA), que indicou diferença significativa entre os tratamentos (tanto para $\mathrm{pH}$ como para a acidez $\mathrm{p}<0,01)$ e foi aplicado o teste de comparação de médias de Tukey $(\mathrm{p}<0,05)$.

Os valores de $\mathrm{pH}$ e acidez da formulação controle (C), "iogurte" de soja não suplementado, não apresentaram diferença significativa quando o "iogurte" foi submetido à fermentação por 6,7 e 8 horas.

TABELA 2. Médias dos resultados experimentais de $\mathrm{pH}$ e acidez das formulações de "iogurte" de soja, segundo delineamento fatorial $3^{3}$ incompleto e da formulação controle para "iogurte" de soja.

\begin{tabular}{|c|c|c|c|c|c|}
\hline \multirow{2}{*}{\multicolumn{4}{|c|}{$\begin{array}{c}\text { Variáveis } \\
\text { Independentes }\end{array}$}} & \multirow{2}{*}{\multicolumn{2}{|c|}{ Respostas }} \\
\hline & & & & & \\
\hline Ensaios & $\mathrm{X}_{1}$ & $\mathrm{X}_{2}$ & $\mathrm{X}_{3}$ & $\mathrm{PH}$ & Acidez (\%) \\
\hline 1 & 5 & 0,5 & 7 & $4,52^{\mathrm{abcd}}$ & $0,42^{\mathrm{DC}}$ \\
\hline 2 & 15 & 0,5 & 7 & $4,6^{\text {bcde }}$ & $0,33^{\mathrm{ab}}$ \\
\hline 3 & 5 & 4,5 & 7 & $4,53^{\text {abcde }}$ & $0,36^{\mathrm{abc}}$ \\
\hline 4 & 15 & 4,5 & 7 & $4,55^{\text {abcde }}$ & $0,38^{\mathrm{abc}}$ \\
\hline 5 & 5 & 2,5 & 6 & $4,53^{\mathrm{abcde}}$ & $0,4^{\mathrm{abc}}$ \\
\hline 6 & 15 & 2,5 & 6 & $4,69^{\mathrm{de}}$ & $0,35^{a b c}$ \\
\hline 7 & 5 & 2,5 & 8 & $4,46^{\mathrm{abc}}$ & $0,44^{c}$ \\
\hline 8 & 15 & 2,5 & 8 & $4,51^{\mathrm{abcd}}$ & $0,4^{\mathrm{abc}}$ \\
\hline 9 & 10 & 0,5 & 6 & $4,47^{\mathrm{abc}}$ & $0,41^{\mathrm{abc}}$ \\
\hline 10 & 10 & 4,5 & 6 & $4,47^{\mathrm{abc}}$ & $0,4^{\mathrm{abc}}$ \\
\hline 11 & 10 & 0,5 & 8 & $4,4^{\mathrm{ab}}$ & $0,41^{\mathrm{abc}}$ \\
\hline 12 & 10 & 4,5 & 8 & $4,37^{\mathrm{a}}$ & $0,36^{\mathrm{abc}}$ \\
\hline 13 & 10 & 2,5 & 7 & $4,62^{\text {cde }}$ & $0,32^{\mathrm{a}}$ \\
\hline 14 & 10 & 2,5 & 7 & $4,52^{\text {abcde }}$ & $0,32^{\mathrm{a}}$ \\
\hline 15 & 10 & 2,5 & 7 & $4,65^{\text {cde }}$ & $0,36^{a b c}$ \\
\hline C & - & - & 6 & $4,72^{\mathrm{e}}$ & $0,38^{a b c}$ \\
\hline $\mathrm{C}$ & - & - & 7 & $4,69^{\text {de }}$ & $0,39^{a b c}$ \\
\hline $\mathrm{C}$ & - & - & 8 & $4,64^{\text {cde }}$ & $0,4^{\mathrm{abc}}$ \\
\hline
\end{tabular}

$\mathrm{X}_{1}=\%$ oligofrutose; $\mathrm{X}_{2}=\%$ de inulina; $\mathrm{X}_{3}=$ tempo de fermentação $(\mathrm{h})$; $\mathrm{C}=$ formulação controle ("iogurte" de soja não suplementado) Médias acompanhadas de letras iguais, na mesma coluna, não diferem entre si $(\mathrm{p}<0,05)$.

As Tabelas 3 e 4 apresentam as estimativas dos coeficientes de regressão e análise de variância (ANOVA) das variáveis respostas $\mathrm{pH}$ e acidez, respectivamente, elaborados a partir dos resultados da Tabela 2.

TABELA 3. Estimativa dos coeficientes de regressão e análise de variância do modelo matemático para a resposta $\mathrm{pH}$

\begin{tabular}{lcccc}
\hline Fatores & Coeficientes & Erro padrão & $\mathrm{t}(8)$ & $\mathrm{p}$ \\
\hline Intercepto $\beta_{0}$ & $4,5967^{*}$ & $0,0256^{*}$ & $179,4830^{*}$ & $0,0000^{*}$ \\
1 Oligofrutose (L) & $0,0388^{*}$ & $0,0157^{*}$ & $2,4708^{*}$ & $0,0387^{*}$ \\
Oligofrutose (Q) & 0,0367 & 0,0231 & 1,5883 & 0,1509 \\
2 Inulina (L) & $-0,0088$ & 0,0157 & $-0,5579$ & 0,5922 \\
Inulina (Q) & $-0,0833^{*}$ & $0,0231^{*}$ & $-3,6098^{*}$ & $0,0069^{*}$ \\
3 Tempo de fermentação (L) & $-0,0525^{*}$ & $0,0157^{*}$ & $-3,3475^{*}$ & $0,0101^{*}$ \\
Tempo de fermentação (Q) & $-0,0858^{*}$ & $0,0231^{*}$ & $-3,7181^{*}$ & $0,0059^{*}$
\end{tabular}

* Significativo a $\mathrm{p}<0,05$

Coeficiente de determinação $\left(R^{2}\right)=0,8547$

Coeficiente de variação $(\%)=0,98$

Falta de ajuste não significativa $(p=0,9304)$

Os resultados apresentados nas Tabela 3 e 4 demonstram que os interceptos foram significativos, in- dicando que o ponto central, para as variáveis independentes, oligofrutose $10 \%(\mathrm{~m} / \mathrm{v})$, inulina $2,5 \%(\mathrm{~m} / \mathrm{v}) \mathrm{e}$ tempo de fermentação de 7 horas, foi escolhido adequadamente.

De acordo com as estimativas dos coeficientes de regressão apresentadas na Tabela 3, a variável mais importante na preparação do "iogurte" foi o tempo de fermentação $\left(\mathrm{X}_{3}\right)$, porque foram significativos tanto $\mathrm{o}$ efeito linear quanto o quadrático desta variável. A resposta $\mathrm{pH}$ também foi influenciada pelo efeito linear da oligofrutose $\left(X_{1}\right)$ e pelo efeito quadrático da inulina $\left(X_{2}\right)$.

O modelo apresentou um coeficiente de determinação razoável $\left(\mathrm{R}^{2}=0,8547\right)$ e a falta de ajuste não foi significativa para a resposta $\mathrm{pH}$, indicando que o modelo pode ser utilizado para fins preditivos.

A análise de variância dos valores de pH do "iogurte" de soja suplementado mostrou que a regressão foi significativa ao nivel de 0,52\%.

O modelo quadrático ajustado pelo método dos mínimos quadrados foi:

$\mathrm{pH}=4,60+0,04 \mathrm{X}_{1}+0,04 \mathrm{X}_{1}{ }^{2-}-0,01 \mathrm{X}_{2}-0,08 \mathrm{X}_{2}^{2}-0,05 \mathrm{X}_{3-} 0,09 \mathrm{X}_{3}^{2}(1)$

onde,

$\mathrm{X}_{1}=$ oligofrutose $(\%)$;

$\mathrm{X}_{2}=$ inulina $(\%)$;

$\mathrm{X}_{3}=$ tempo de fermentação $(\mathrm{h})$.

A região de combinação binária entre as variáveis $\mathrm{X}_{2}$ e $\mathrm{X}_{3}$ pode ser observada através das curvas de nivel apresentadas na Figura 2. A figura mostra as regiões de contorno da superficie de resposta para a variável dependente $\mathrm{pH}$, obtidas pelo modelo matemático, fixando-se a variável $\mathrm{X}_{1}$ no nivel codificado +1 (oligofrutose na concentração de $15 \%$ ). Este nivel maior foi escolhido para conferir doçura ao produto, pois nenhum outro açúcar foi adicionado. Além disso, a oligofrutose tem a função prebiótica.

A fermentação de iogurte de leite de vaca deve ser interrompida quando o valor de $\mathrm{pH}$ deste produto atinge valores na faixa de 4,4 a 4,5, o que ocorre em aproximadamente 4 horas, quando submetido à temperatura de $42^{\circ} \mathrm{C}$ [32]. Este valor é considerado o ideal para promover a coagulação das proteínas do leite e, conseqüente, formação de gel. Porém, o pH considerado ótimo para formação de gel em extrato de soja é de 4,5-4,6, sendo que a composição deste substrato (sacarose como o principal carboidrato fermentável) torna o processo de coagulação mais lento [5]. Valores de $\mathrm{pH}$ encontrados em diferentes formulações de "iogurte" de soja variaram entre 4,4 e 4,8 [4, 32, 33, 35]. O valor de referência para $\mathrm{pH}$ adotado neste trabalho foi de 4,6, que representa uma média dos valores relatados na literatura.

Segundo TAMINE \& ROBINSON [32] iogurtes de leite de vaca devem apresentar acidez em torno de 0,70 0,72\% de ácido lático. Entretanto, a composição do ex- 
trato de soja não é totalmente adequada à formação de um "iogurte" com acidez e textura semelhantes ao iogurte de leite de vaca. Por esse motivo, o extrato de soja é freqüentemente suplementado com ingredientes que melhoram algumas características físicas e químicas do "iogurte" produzido. TRINDADE et al. [33] afirmaram que "iogurtes" elaborados a partir de extrato de soja sem suplementação atingem valores de acidez entre 0,24\% (4 horas de fermentação) e 0,33\% (6 horas de fermentação). Os ingredientes normalmente adicionados ao extrato de soja são leite de vaca, soro de leite, proteínas do leite, lactose, frutose, sacarose, leite em pó desengordurado e gelatina, que proporcionam a produção de "iogurtes" com acidez que varia entre 0,70 e $0,85 \%[4,19,22,28]$. A ausência destes suplementos no "iogurte" de soja desenvolvido neste trabalho inviabiliza a obtenção de valores de acidez semelhantes. Por esse motivo a acidez de 0,37\% foi adotada como valor de referência, representando a média de acidez encontrada nas diferentes formulações analisadas.

De acordo com a Figura 2, o "iogurte" com $\mathrm{pH}$ final de 4,6 pode ser obtido utilizando-se $\mathrm{X}_{2}$ (inulina) no nível codificado $0(2,5 \% \mathrm{~m} / \mathrm{v})$ e $\mathrm{X}_{3}$ (tempo de fermentação) no nivel codificado -1 (6 horas).

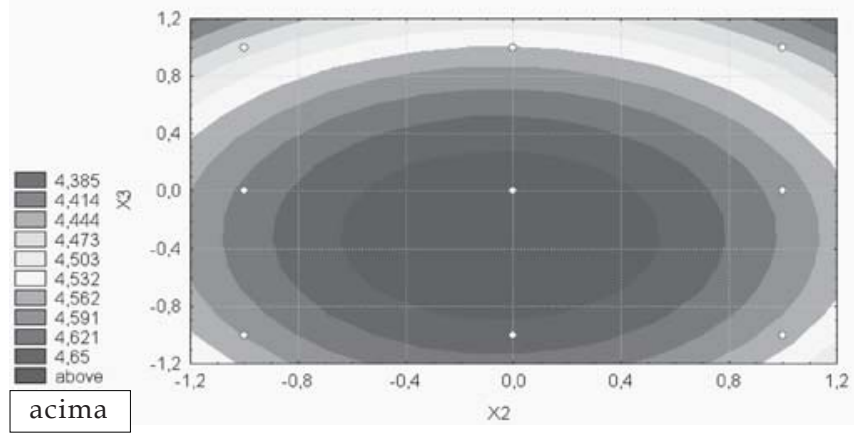

FIGURA 2. Contorno da superficie de resposta do pH, fixando-se a variável $\mathrm{X}_{1}$ no nível codificado +1 .

A Tabela 4 indica a estimativa dos coeficientes de regressão para a resposta acidez.

TABELA 4. Estimativa dos coeficientes de regressão e análise de variância do modelo matemático para a resposta acidez

\begin{tabular}{lcccc}
\hline Fatores & Coeficientes & Erro padrão & $\mathrm{t}(8)$ & $\mathrm{p}$ \\
\hline Intercepto $\beta_{0}$ & $0,3333^{*}$ & $0,0171^{*}$ & $19,5296^{*}$ & $0,0000^{*}$ \\
1 Oligofrutose (L) & $-0,0200$ & 0,0105 & $-1,9135$ & 0,0920 \\
Oligofrutose (Q) & 0,0208 & 0,0154 & 1,3541 & 0,2127 \\
2 Inulina (L) & $-0,0088$ & 0,0105 & $-0,8372$ & 0,4268 \\
Inulina (Q) & 0,0183 & 0,0154 & 1,1916 & 0,2676 \\
3 Tempo de fermentação (L) & 0,0063 & 0,0105 & 0,5980 & 0,5664 \\
Tempo de fermentação (Q) & $0,0433^{*}$ & $0,0154^{*}$ & $2,8166^{*}$ & $0,0226^{*}$ \\
\hline
\end{tabular}

* Significativo a $\mathrm{p}<0,052$

Coeficiente de determinação $\left(R^{2}\right)=0,6485$

Coeficiente de variação $(\%)=7,84$

Falta de ajuste não significativa $(p=0,3914)$

De acordo com a estimativa do coeficiente de regressão apresentada na Tabela 4, a resposta acidez foi influenciada apenas pelo efeito quadrático do tempo de fermentação $\left(\mathrm{X}_{3}\right)$.

A falta de ajuste não foi significativa para a resposta acidez, indicando que o modelo pode ser utilizado para fins preditivos mesmo que $\mathrm{R}^{2}$ não tenha sido satisfatório [28].

A análise de variância dos valores de acidez do "iogurte" de soja mostrou que a regressão foi significativa ao nivel de 10,26\%.

O modelo quadrático ajustado pelo método dos mínimos quadrados foi:

Acidez $\%=0,33-0,02 \mathrm{X}_{1}+0,02 \mathrm{X}_{1}^{2-} 0,01 \mathrm{X}_{2}+0,02 \mathrm{X}_{2}^{2}+0,01 \mathrm{X}_{3}+0,04 \mathrm{X}_{3}^{2}$

sendo, $\mathrm{X}_{1}=$ oligofrutose $(\%) ; \mathrm{X}_{2}=$ inulina $(\%)$ e $\mathrm{X}_{3}=$ tempo de fermentação (h).

A região de combinação binária entre as variáveis $\mathrm{X}_{2}$ e $\mathrm{X}_{3}$ pode ser observada através das curvas de nível apresentadas na Figura 3. A figura mostra as regiões de contorno da superficie de resposta para a variável dependente acidez, obtidas pelo modelo matemático, fixando-se a variável $\mathrm{X}_{1}$ no nivel codificado +1 (oligofrutose na concentração de $15 \%$ ). De acordo com a Figura 3, o "iogurte" com acidez titulável de $0,37 \%$ pode ser obtido utilizando-se $\mathrm{X}_{2}$ (inulina) no nivel codificado $0(2,5 \% \mathrm{~m} / \mathrm{v})$ e $\mathrm{X}_{3}$ (tempo de fermentação) no nível codificado -1 (6 horas).

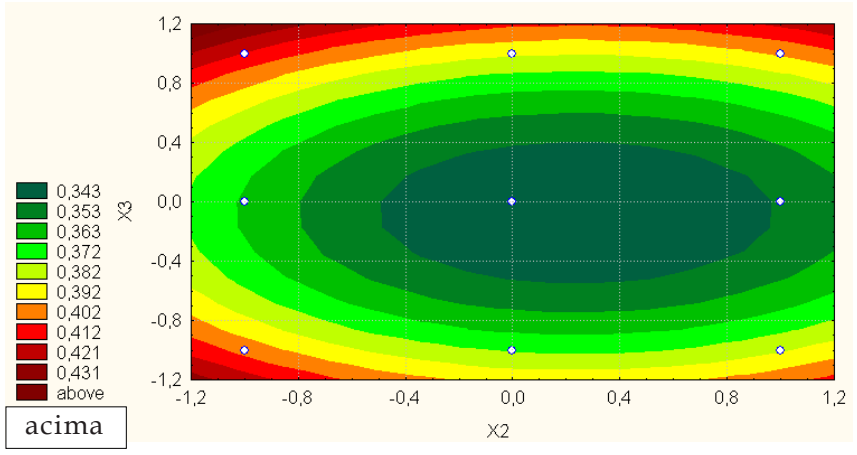

FIGURA 3. Contorno da superfície de resposta da acidez, fixando-se a variável $\mathrm{X}_{1}$ no nível codificado +1 .

A otimização conjunta bilateral tendo como valor de referência 4,6 para o $\mathrm{pH}$ e $0,37 \%$ para a acidez indicou a formulação contendo $14,24 \%$ de oligofrutose $\left(X_{1}\right)$ e $4,43 \%$ de inulina $\left(X_{2}\right)$ e 6 horas de fermentação $\left(X_{3}\right)$ como as melhores condições para a elaboração do iogurte de soja. Na prática, o "iogurte" produzido sob estas condições, apresentou pH de 4,63 e acidez de 0,37\%, o que confirma os valores estimados na otimização para as variáveis dependentes. O produto obtido apresentou boa aceitabilidade [14].

Os mapas de contorno das superficies mostram que os dados fornecidos pela otimização conjunta bilateral estimaram pontos para a formulação do "iogurte" com as características esperadas ( $\mathrm{pH}$ e acidez). 
Oligofrutose e inulina são importantes agentes prebióticos que influenciam beneficamente a flora do trato-gastrintestinal de humanos. Foi verificado que a ingestão de $5 \mathrm{~g} /$ dia de oligofrutose é suficiente para elevar o número de bifidobactérias [24]. De acordo com REID et al. [26] doses efetivas de prebióticos parecem ser,cerca, de 1 a $3 \mathrm{~g} /$ dia para crianças e 5 a 15g/dia para adultos. Entretanto, os prebióticos geralmente são misturas de carboidratos, com diferentes graus de polimerização, dificultando a determinação da dose efetiva.

\section{2 - Composição química}

A formulação otimizada de "iogurte" de soja suplementado com prebióticos apresentou $16,2 \%$ de carboidratos, 2,01\% de lipídios, 3,54\% de proteínas, 0,40\% de cinzas e $77,85 \%$ de umidade. O teor de cálcio foi de $37 \mathrm{mg} / 100 \mathrm{~g}$, de ferro de $0,99 \mathrm{mg} / 100 \mathrm{~g}$ e de sódio de $15 \mathrm{mg} /$ $100 \mathrm{~g}$. Comparando-se com a composição de iogurte de leite de vaca natural integral (industrializado), não há diferenças nos teores de proteínas e lipídios, que segundo PHILIPPI, SZARFARC \& LATTERZA [23], são de $3,47 \mathrm{~g} / 100 \mathrm{~g}$ e 2,1g/100 g, respectivamente. Entretanto, o teor de carboidratos do "iogurte" de soja é maior que o teor de carboidratos do iogurte de leite de vaca, que segundo PHILIPPI, SZARFARC \& LATTERZA [23], é de $4,65 \%$. Isto se deve ao fato do iogurte natural em consideração, não ser adicionado de açúcar, sendo quantificada apenas a lactose presente no leite. Embora o teor de carboidratos do iogurte de leite de vaca varie em função da região de produção, o valor médio é de $16 \%$.

YAZICI, ALVAREZ \& HANSEN [35] desenvolveram "iogurte" de soja formulado a partir de farinha de soja suplementada com isolado protéico de soja, xarope de milho, glucose, sacarose e lactogluconato de cálcio, visando a melhoria no teor deste mineral no "iogurte". A composição química do produto foi de 5,4\% de proteínas, 6,6\% de carboidratos, 1,5\% de lipídIos, 1,6\% de cinzas e o teor de cálcio foi de $190 \mathrm{mg} / 100 \mathrm{~g}$.

LEE, MORR \& SEO [19] avaliaram o teor protéico de "iogurte" de soja suplementado com concentrado protéico de soro ou leite em pó desengordurado. O produto suplementado com concentrado protéico apresentou $8,12 \%$ de proteínas, enquanto o suplementado com leite em pó desengordurado apresentou $7,28 \%$, sendo que ambos obtiveram maior concentração protéica, se comparados ao "iogurte" de soja elaborado neste trabalho.

A formulação desenvolvida por UMBELINO, CARDELLO \& ROSSI [34], composta por extrato aquoso de soja, lactose, óleo de soja, sacarose e leite em pó desnatado, apresentou a seguinte composição química: $3,4 \%$ de proteínas, $2,75 \%$ de lipídeos e $12,05 \%$ de carboidratos.

Apesar do iogurte de leite de vaca possuir maior teor de cálcio (120mg/100g), o "iogurte" de soja suplementado com oligofrutose e inulina pode favorecer a absorção intestinal de cálcio, pois de acordo com COUDRAY et al. [6], a mistura de inulina e frutooligos- sacarídeos melhora a absorção intestinal e o balanço deste mineral em ratos.

O teor de ferro do "iogurte" de soja é maior que o do iogurte de leite de vaca $(0,05 \mathrm{mg} / 100 \mathrm{~g})$, constituindo uma boa opção para tratamento de anemia ferropriva. Com relação ao sódio, o iogurte de leite de vaca possui maior quantidade deste mineral (46mg/100g).

A dosagem de ácido lático indicou um valor de 0,34\%, enquanto que o "iogurte" não suplementado com prebióticos apresentou $0,30 \%$ de ácido lático. A produção de ácidos orgânicos como o ácido acético e ácido lático na forma $\mathrm{L}(+)$, produzido pelo $S$. thermophilus e a concomitante redução do $\mathrm{pH}$ restringem o crescimento de microrganismos patogênicos e putrefativos ácido-sensiveis [17].

\section{4 - CONCLUSÕES}

A otimização conjunta bilateral indicou que a suplementação do "iogurte" de soja deve ser feita adicionando-se $14,24 \%$ de oligofrutose; 4,43\% de inulina e tempo de fermentação de 6 horas. O produto obtido nestas condições, mostrou-se como uma boa opção para o consumo de derivados de soja e substâncias prebióticas.

\section{5 - REFERÊNCIAS BIBLIOGRÁFICAS}

[1] A. O. A. C. Official Methods of Analysis, $15^{\text {th }}$ ed. Association of Official Analytical Chemist. Washington, D.C., 1995.

[2] BONA, E.; BORSATO, D.; SILVA, R. S. S. F.; BENETASSO, D. L.; SOUZA, D. A. Planejamento e otimização de sistemas mistos controlados por variáveis qualitativas e quantitativas. Acta Scientarium, v. 24, n. 6, p. 1843-1850, 2002.

[3] BOX, G. E. P.; BENHKEN, D. W. Some new three level designs for the study of quantitative variables. Techometrics, v.2, n.4, p. 455-475, 1960.

[4] BUONO, M. A.; SETSER, C.; ERICKSON, L. E; FUNG, D. Y. C. Soymilk yogurt: Sensory evaluation and chemical measurement. Journal of Food Science, v. 55, n. 2, p.528-531, 1990.

[5] CHUMCHUERE, S.; ROBINSON, R. K. Selection of starter culture for the fermentation of soya milk. Food Microbiology, v. 16, p. 129-137, 1999.

[6] COUdRAY, C.; TRESSOL, J. C. GUEUX, E.; RAYSSIGUIER, Y. Effects of inulin-type fructans of different chain length and type of branching on intestinal absorption and balance of calcium and magnesium in rats. Europian Journal of Nutrition, v. 42, n. 2, p. 91-98, 2003.

[7] DE ANGelis, R. C. Fome Oculta: Bases fisiológicas para reduzir seu risco. São Paulo: Atheneu, 1999.

[8] DE ANGELIS, R. C. Alimentos de origem vegetal são saudáveis: verdades e alguns questionamentos. Nutrição em Pauta, ano X, n. 57, p. 30-34, 2002.

[9] DE BOEVER, P.; DEPLANCKE, B.; VERSTRAETE, W. Fermentation by gut microbiota cultured in a simulator of the human intestinal microbial ecosystem is improved by supplementing a soygerm powder. American Journal of Clinical Nutrition, v. 130, p. 2599-2606, 2000.

[10] DERRINGER, G.; SUICH, R. Simultaneous optimization 
of several response variables. Journal of Quality Technology, v.12, p. 214-219, 1980

[11] FAO/WHO.Guidelines for the evaluation of probiotics in food.Food and agriculture Organization of the United Nations and World Health Organization Working group report. London Ontario, Canadá,2002. Disponível: ftp:/ /ftp.fao.org/es/esn/food/wgreport2.pdf. Acesso em: janeiro/ 2005.

[12] FERREIRA, C. L. L. F. Acidez em leites e produtos lácteos: aspectos fundamentais. Viçosa: UFV, 1999, $26 \mathrm{p}$.

[13] FERREIRA, C. L. L. F. Grupo de Bactérias láticas- Caracterização tecnológica e aplicação de bactérias probióticas In: FERREIRA, C. L. L. F (Ed) Prebióticos e Probióticos: atualizaqção e prospecção.Viçosa: Célia L.L.ferreira,2003. Cap.1,p.7-33.

[14] FUCHS, R. H. B. Iogurte de soja suplementado com oligofrutose e inulina. Londrina, 2004. 99p. Dissertação (Mestrado em Biotecnologia) - Universidade Estadual de Londrina.

[15] FULLER, R. A review: probiotics in man and animals. Journal of Applied Bacteriology, v.66, p. 365-378, 1989.

[16] GIBSON, G.R.; ROBERFROID, M. Dietary modulation of the human colonic microbiota: introducing the concept of prebiotics. Journal of Nutrition, v.125, p. 1401-1412, 1995.

[17] GOMES, A. M. P.; MALCATA, F. X. Bifidobacterium $s p$. and Lactobacillus acidophilus: biological, biochemical, technological and therapeutical properties relevant for use as probiotics. Trends in Food science \& Technology, v. 10, p. 139-157, 1999.

[18] KAYSER, F..H. Safety aspects of enterococci from the medical point of view. International Journal of Food Microbiology,v.88,n.2,3,Dec. p.255-262, 2003.

[19] LEE, S. Y.; MORR, C. V.; SEO, A. Comparison of milkbased and soymilk-based yogurt. Journal of Food Science, v. 55, n. 2, 1990.

[20] LOSADA, M. A.; OLlEROS, T. Towards a healthier diet for the cólon: the influence of fructoologosaccharides and lactobacilli on intestinal health. Nutrition Research, v. 22, p. 71-84, 2002.

[21] MARTEAU, P. Safety aspects of probiotics products. Scandinavian Journal of Nutrition,45:22-24, 2001.

[22] NSOFOR, L. M.; CHUKWU, E. U. Sensory evaluation of soy milk-based yoghurt. Journal of Food Science \& Technology, v. 29, n. 5, p. 301-303, 1992.
[23] PHILIPPI, S. T.; SZARFARC, S. C.; LATTERZA, A. R. Virtual Nutrição [software], Versão 1.0, for Windows. Departamento de Nutrição/ Faculdade de Saúde Pública/ USP. São Paulo, 1996.

[24] RAO,V.A. The prebiotic properties of oligofructose at low intake levels. Nutrition Research,v. 21, n. 6, p. 843-848,2001.

[25] RASTALL, R. A.; MAITIN, V. Prebiotics and synbiotics: towards the next generation. Current Opinion in Biotechnology, n. 13, p. 490-496, 2002.

[26] REID,G.;SANDERS,M.E.;GASKINS,H.R. GIBSON G. R., MERCENIER, A., RAST ALL, R. ROBERFROID, M. ROWLAND, L. CHERBUT, C. KLAENHAMMER, T. R. New scientific paradigms for probiotics and prebiotics. Journal of Clinical Gastroenterology, v. 37, n. 2, p. 105-118, Aug.,2003..

[27] ROBERFROID, M. B. Concept in functional foods: the case of inulin and oligofructose. Journal of Nutrition, (Suppl.), v. 129, p. 1398-1401, 1999.

[28] ROSSI, E. A.; FARIA, J. B.; BORSATO, D.; BALDOCHI, F. L. Otimização de um sistema estabilizante para o "iogurte" de soja. Alimentos e Nutrição, v. 2, p. 83-92, 1990.

[29] RYCROFT, C. E.; JONES, M.R.; GIBSON, G.R.; RASTALL, R.A. A comparative in vitro evaluation of the fermentation properties of prebiotic oligosaccharides, Journal of Applied Microbiology, v. 91, p. 878-887, 2001.

[30] SILVA, D.J. Análise de Alimentos: Métodos Químicos e Biológicos. Viçosa: UFV, p.110-114, 1981.

[31] STATSOFT, Inc., STATISTICA for Windows (Computer Program Manual). Tulsa, Oklahoma, USA, 1995.

[32] TAMINE, A. Y.; ROBINSON, R. K. Yogurt: science and technology. Oxford: Pergamon, 1985, 431 p.

[33] TRINDADE, C. S. F.; TERZI, S. C.; TRUGO, L. C.; MODESTA, R. C. D.; COURI, S. Development and sensory evaluation of soy milk based yoghurt. Archives Latinoamericanos of Nutrition, v. 51, n. 1, p. 100-104, 2001.

[34] UMBelino, D. C.; CARDEllo, H. M. A. B.; ROSSI, E. A. Efeito de diferentes sais de ferro sobre as caracteristicas sensoriais do "iogurte"de soja. Archives Latinoamericanos of Nutrition, v. 51 , n. 2, p. 199203, 2001.

[35] YAZICI, F.; ALVAREZ, V. B.; HANSEN, P. M. T. Fermentation and properties of calcium-fortified soy milk yogurt. Journal of Food Science, v. 62, n. 3 , 1997. 
O arquivo disponível sofreu correções conforme ERRATA publicada no Volume 25 Número 2 da revista. 